\title{
MicroRNA-1298-5p inhibits the tumorigenesis of breast cancer by targeting E2F1
}

\author{
JIE ZHANG $^{1 *}$, CHENYANG HU ${ }^{2 *}$, DAWEI HU ${ }^{1}$ and ZHIMIN FAN ${ }^{2}$ \\ ${ }^{1}$ Department of Breast Surgery, The Affiliated Hospital of Chengde Medical College, Chengde, Hebei 067000; \\ ${ }^{2}$ Department of Breast Surgery, The First Bethune Hospital of Jilin University, Changchun, Jilin 130021, P.R. China
}

Received July 2, 2020; Accepted June 3, 2021

DOI: 10.3892/ol.2021.12921

\begin{abstract}
Studies performed in the last two decades have identified microRNA (miR)-1298-5p to display tumor-suppressive functions in several types of malignancy. In addition, the regulatory role of E2F transcription factor 1 (E2F1) has been reported in multiple types of cancer, including breast cancer (BC). However, whether miR-1298-5p participates in $\mathrm{BC}$ progression and whether a regulatory association exists between miR-1298-5p and E2F1 remains to be explored. The present study aimed to determine the role of miR-1298-5p and its interaction with E2F1 in BC. The expression of miR-1298-5p and E2F1 was examined by reverse transcription-quantitative PCR and western blot assays. The viability and proliferative capacity of $\mathrm{BC}$ cells were evaluated by Cell Counting Kit- 8 and 5-bromo-2'-deoxyuridine assays, respectively. The apoptotic rate was assessed by the caspase- 3 activity assay and flow cytometry; the protein expression levels of vimentin and E-cadherin were evaluated by western blotting. In addition, the adhesive and migratory abilities of BC cells were determined by conducting cell adhesion and wound healing assay, respectively. The target relationship between miR-1298-5p and E2F1 was validated by the luciferase reporter assay. The results of the present study revealed that the levels of miR-1298-5p were downregulated in BC tissues and cells compared with those in normal breast tissues and cells, respectively. In addition, miR-1298-5p was demonstrated to inhibit the proliferation, adhesion and migration of $\mathrm{BC}$ cells and to promote $\mathrm{BC}$ cell
\end{abstract}

Correspondence to: Dr Dawei Hu, Department of Breast Surgery, The Affiliated Hospital of Chengde Medical College, 36 Nanyingzi, Chengde, Hebei 067000, P.R. China

E-mail: daweihu697@163.com

Dr Zhimin Fan, Department of Breast Surgery, The First Bethune Hospital of Jilin University, 71 Xinmin, Changchun, Jilin 130021, P.R. China

E-mail: fanzhimin68@163.com

${ }^{*}$ Contributed equally

Key words: breast cancer, cell proliferation, apoptosis, miR-1298-5p, E2F transcription factor 1 apoptosis. E2F1 was verified as a target gene of miR-1298-5p using the luciferase reporter assay. Additionally, E2F1 exhibited an opposite expression pattern compared with that of miR-1298-5p in BC tissues. Furthermore, the downregulation of miR-1298-5p in BC cells was reversed by silencing E2F1. Overall, the results of the present study suggested that miR-1298-5p repressed BC cell proliferation, adhesion and migration, and enhanced $\mathrm{BC}$ cell apoptosis by downregulating E2F1.

\section{Introduction}

Breast cancer (BC) is a malignant growth that develops and spreads from the mammary system and is the leading cause of mortality among women (6.6\% mortality rate) worldwide in $2018(1,2)$. Although numerous advanced technologies such as breast-conserving surgery, mastectomy, chemotherapy and radiation therapy are employed to treat various stages of $\mathrm{BC}$, the 5-year survival rate of patients diagnosed during 2009 and 2015 remains low (98\% for stage I, 92\% for stage II, 75\% for stage III, and $27 \%$ for stage IV), especially among patients with stage IV BC, partly due to the high recurrence rate $(3,4)$. For this reason, new diagnostic and therapeutic targets for $\mathrm{BC}$ need to be urgently identified.

MicroRNAs (miRNAs) are a class of endogenous small RNA molecules with 20-25 nucleotides that have been documented to affect the expression of their target genes $(5,6)$. In addition, a growing number of studies have reported that miRNAs can serve as oncogenes or tumor suppressor genes (7). As a diagnostic and therapeutic targets, miRNAs can regulate the tumorigenesis of various types of cancer, including BC (8-10). In BC, miR-1287-5p and miR-137 have been identified to inhibit BC progression $(11,12)$. miR-1298-5p was first reported to regulate the proliferation and migration of vascular smooth muscle cells by targeting connexin 43 (13). Further studies have revealed that miR-1298-5p is expressed at low levels in tissues and cells of a number of types of cancer, such as glioma (13), gastric cancer (14), bladder cancer (15) and lung cancer (16). In addition, this miR-1298-5p contributes to the proliferation, migration and invasion of various cancer cell types, including glioma, gastric cancer, bladder cancer and lung cancer (14-17). A previous BC study has reported that the overexpression of miR-1298 targets disintegrin and metalloproteinase domain-containing protein 9 (ADAM9) 
and inhibits malignant processes in vivo and in vitro (18). The tumor-suppressive function of miR-1298-5p has been acknowledged in the tumorigenesis of several types of cancer, such as glioma (13) and lung cancer (16). However, the roles of miR-1298-5p and its downstream regulators in BC development need to be further investigated.

The E2F family of transcription factors regulate the expression of crucial genes involved in the cell cycle, differentiation and apoptosis, such as pRB, p107 and p130 (19,20). E2F transcription factor 1 (E2F1) was the first member of the E2F family to be cloned, and has been demonstrated to modulate cell proliferation and apoptosis by activating its downstream target genes, such as p53 and DP-1 (21-23). Considering the importance of cell proliferation and apoptosis in the development of carcinoma, the effects of E2F1 on tumorigenesis have been investigated in previous studies. For instance, E2F1 has been demonstrated to serve a crucial role in the metastasis and aggressiveness of gastric (24), lung (25) and prostate (26) cancer, glioma (27) and hepatocellular carcinoma (28). In addition, E2F1 can serve as a tumor promoter or suppressor; the dual function of $\mathrm{E} 2 \mathrm{~F} 1$ has been observed in $\mathrm{BC}$ development (29-31). Notably, numerous studies have reported the critical role of the miRNA/E2F1 axis in the carcinogenesis of BC (32-34). In myeloid cells, bioinformatics analysis has revealed that $\mathrm{E} 2 \mathrm{~F} 1$ may be targeted by miR-1298-5p to regulate the cell cycle (35). However, no studies have confirmed whether miR-1298-5p may target E2F1 to contribute to BC progression to date.

The present study aimed to investigate the regulatory role of miR-1298-5p and its potential target E2F1 in the pathogenesis of BC. It was hypothesized that an association existed between BC and miR-1298-5p. The results of the present study may provide new targets for $\mathrm{BC}$ diagnosis and treatment.

\section{Materials and methods}

Clinical samples. Paired breast cancer and adjacent normal tissue specimens were collected from 35 patients with $\mathrm{BC}$ who underwent surgery prior to therapeutic intervention at The First Bethune Hospital of Jilin University (Changchun, China) between February 2017 and December 2019. The age range of the patients was 28 to 54 years (mean $\pm \mathrm{SD}, 40.75 \pm 12.37$ years). All subjects provided written informed consent before specimen collection, and all experiments were approved by the Ethics Committee of The First Bethune Hospital of Jilin University (approval no. 201021-005). The clinicopathological characteristics of the patients are presented in Table I.

Cell lines and culture. Human BC cell lines T-47D, SK-BR-3, MDA-MB-231, MCF7 and BT-474, and the normal breast cell line MCF10A were purchased from the American Type Culture Collection. MCF10A cells were maintained in Mammary Epithelial Cell Growth Basal Medium (cat. no. CC3150; Lonza Group, Ltd.) supplemented with $13 \mathrm{mg} / \mathrm{ml}$ bovine pituitary extract (Thermo Fisher Scientific, Inc.), $0.5 \mathrm{mg} / \mathrm{ml}$ hydrocortisone (Sigma-Aldrich; Merck $\mathrm{KGaA}$ ), $10 \mu \mathrm{g} / \mathrm{ml}$ human epidermal growth factor (Lonza Group, Ltd.), $5 \mathrm{mg} / \mathrm{ml}$ bovine insulin (Sigma-Aldrich), $100 \mathrm{ng} / \mathrm{ml}$ cholera toxin (cat. no. C8052; Sigma-Aldrich; Merck KGaA), and $100 \mathrm{U} / \mathrm{ml}$ penicillin-streptomycin
Mixtures (Lonza Group, Inc.). The RPMI-1640 medium (Gibco; Thermo Fisher Scientific, Inc.) supplemented with $10 \%$ fetal bovine serum (Gibco; Thermo Fisher Scientific, Inc.), and $100 \mathrm{U} / \mathrm{ml}$ penicillin-streptomycin Mixtures was used to culture the BC cells. All cell lines were cultured or incubated at $37^{\circ} \mathrm{C}$ in an incubator with $5 \% \mathrm{CO}_{2}$.

Reverse transcription-quantitative PCR (RT- $q P C R)$. The RNA from the tissues or cells was extracted using TRIzol ${ }^{\circledR}$ reagent (Invitrogen; Thermo Fisher Scientific, Inc.). The expression of miR-1298-5p was detected using the All-in-One ${ }^{\mathrm{TM}}$ miRNA RT-qPCR Detection kit (GeneCopoeia, Inc.). The PrimeScript $^{\mathrm{TM}}$ RT reagent kit (Takara Bio, Inc.) and SYBR ${ }^{\circledR}$ Premix Ex Taq (Takara Bio, Inc.) were used to perform the reverse transcription and $\mathrm{qPCR}$, respectively, to determine the expression levels of E2F1. The thermocycling parameters were as follows: Initial denaturation at $95^{\circ} \mathrm{C}$ for $30 \mathrm{sec}$, followed by 40 cycles of $95^{\circ} \mathrm{C}$ for $5 \mathrm{sec}$ and $60^{\circ} \mathrm{C}$ for $30 \mathrm{sec}$. All procedures were performed according to the manufacturer's instructions. U6 and GAPDH were used as the normalization controls for miR-1298-5p and E2F1, respectively. The relative expression levels were calculated using the $2^{-\Delta \Delta \mathrm{Cq}}$ method (36). The primer sequences are presented in Table II.

Cell transfection. The miR-1298-5p mimics, miR-1298-5p inhibitor, E2F1 small interfering RNA (siRNA) and their corresponding negative controls (NC) were designed and purchased from Guangzhou RiboBio Co., Ltd.; the sequences are presented in Table SI. T47D and SKBR3 cells in the logarithmic growth phase were digested with trypsin and collected by centrifugation at $3,850 \times \mathrm{g}$ and $37^{\circ} \mathrm{C}$ for $5 \mathrm{~min}$. The cells were resuspended in the culture medium and seeded into 6- or 96-well plates at a density of $1 \times 10^{6}$ or $5 \times 10^{3}$ cells/well. Following culture with $5 \% \mathrm{CO}_{2}$ at $37^{\circ} \mathrm{C}$ for $12 \mathrm{~h}, 100 \mathrm{nM}$ miR-1298-5p mimics, inhibitor, E2F1 siRNA or the corresponding NC were transfected into the T47D and SKBR3 cells using the Lipofectamine ${ }^{\circledR} 2000$ transfection reagent (Invitrogen; Thermo Fisher Scientific, Inc.) at $37^{\circ} \mathrm{C}$ for $6 \mathrm{~h}$, and the culture medium was replaced. After $48 \mathrm{~h}$, the transfection efficiency was determined by RT-qPCR. The transfected cells were subsequently harvested and prepared for further assays. Untransfected cells were used as the blank control group.

Cell viability assay. The Cell Counting Kit-8 (CCK-8; cat. no. B34304; Bimake) was used to evaluate the viability of the T47D and SKBR3 cells according to the manufacturer's instructions. The cells were harvested and plated in 96-well plates at a density of $3 \times 10^{3}$ cells/well following transfection and cultured for 1, 2, 3 and 4 days. At each time point, $10 \mu \mathrm{l} \mathrm{CCK-8}$ solution was added into each cell well and incubated for $2 \mathrm{~h}$ at $37^{\circ} \mathrm{C}$ with $5 \% \mathrm{CO}_{2}$. The absorbance at $450 \mathrm{~nm}$ was identified using a microplate reader (Bio-Rad Laboratories, Inc.).

Cell proliferation assay. The DNA synthesis capacity was determined using the 5-bromo-2'-deoxyuridine (BrdU) Cell Proliferation ELISA kit (Abcam) according to the manufacturer's instructions to measure the proliferative capacity of T-47D and SK-BR-3 cells. The transfected cells were collected with trypsin and plated in 96-well plates at a density of $2 \times 10^{5}$ cells/well. Subsequently, $20 \mu 11 \mathrm{X}$ BrdU labeling 
Table I. Clinicopathological characteristics of 35 patients with breast cancer.

\begin{tabular}{lcc}
\hline & \multicolumn{2}{c}{ Cases (n=35) } \\
\cline { 2 - 3 } Characteristic & Number & Frequency (\%) \\
\hline Onset age, years & & \\
$<40$ & 15 & 42.9 \\
$\geq 40$ & 20 & 57.1 \\
Tumor site & & \\
Unilateral & 32 & 91.4 \\
Bilateral & 3 & 8.6 \\
Pathological diagnosis & & \\
Ductal carcinoma & 28 & 80.0 \\
Lobular carcinoma & 5 & 14.3 \\
Other neoplasm & 2 & 5.7 \\
Estrogen receptor & & \\
Positive & 6 & 17.1 \\
Negative & 29 & 82.9 \\
HER-2/neu & & \\
Positive & 9 & 25.7 \\
Negative & 26 & 74.3 \\
Pathological stage & & \\
I & 8 & 22.9 \\
II & 6 & 57.1 \\
III & 1 & 2.9 \\
IV & & \\
\hline
\end{tabular}

Table II. Primer sequences for reverse transcription-quantitative PCR.

\begin{tabular}{ll}
\hline Target & \multicolumn{1}{c}{ Primer sequences (5'-3') } \\
\hline miR-1298-5p & F: GCCGTTCATTCGGCTGTCC \\
R6 & F: GTGCAGGGTCCGAGGTATTC \\
E2F1 & R: AACGCTTCACGCAGCACA \\
& F:ACGCTATGAGACCTCACTGAA \\
GAPDH & R: TCCTGGGTCAACCCCTCAAG \\
& F: AGCCACATCGCTCAGACAC \\
& R: GCCCAATACGACCAAATCC \\
\hline
\end{tabular}

miR, microRNA; E2F1,E2F transcription factor 1; F, forward; R, reverse.

solution was added to the each well to label newly synthetized DNA and incubated at $37^{\circ} \mathrm{C}$ for $2 \mathrm{~h}$. Following the incubation, the medium was replaced with $200 \mu$ l Fixing Solution and incubated at room temperature for $30 \mathrm{~min}$. The cells were washed thrice with $1 \mathrm{X}$ Wash Buffer, $100 \mu \mathrm{l}$ anti-BrdU monoclonal antibody solution was added, and the cells were incubated at room temperature for $1 \mathrm{~h}$. Subsequently, the cells were consecutively incubated with $100 \mu$ l Peroxidase Goat Anti-Mouse IgG Conjugate and $100 \mu$ l of TMB substrate solution at room temperature for $30 \mathrm{~min}$. Finally, the absorbance at $450 \mathrm{~nm}$ was measured using a microplate reader.

Caspase-3 activity assay. The caspase- 3 activity of the T-47D and SK-BR-3 cells was examined using the Caspase-3 Colorimetric Assay kit (Medical and Biological Laboratories Co., Ltd.) according to the manufacturer's instructions. First, $2 \times 10^{5}$ transfected cells were collected and lysed using lysis buffer. Subsequently, $50 \mu 1$ of the cell lysates were added to 96-well plates, and $50 \mu 1$ reaction buffer and $5 \mu 1$ caspase-3 substrate were added into each cell well. The mixture was incubated at $37^{\circ} \mathrm{C}$ for $1 \mathrm{~h}$. Finally, the absorbance at $405 \mathrm{~nm}$ was measured using a microplate reader. The enzymatic activity of caspase- 3 normalized to that of the control group was used for statistical analysis.

Apoptosis assay. The Annexin V/propidium iodide (PI) double staining kit (BD Biosciences) was used to stain the cells according to the manufacturer's protocol. T-47D and SK-BR-3 cells were seeded in 24-well plates at a density of $3 \times 10^{5}$ cells/well, transfected and collected at $48 \mathrm{~h}$ post-transfection. Subsequently, the cells were washed twice with cold PBS and resuscitated in $1 \mathrm{X}$ binding buffer. The cells were then stained in the dark with $5 \mu \mathrm{l}$ Annexin V-FITC for $15 \mathrm{~min}$ and $5 \mu \mathrm{l}$ PI for $10 \mathrm{~min}$ at room temperature. Apoptosis was detected using a BD FACSVerse flow cytometer (BD Biosciences) and analyzed using FlowJo v9.96 (FlowJo LLC).

Cell adhesion assay. The cell adhesion assay was performed as previously described. Briefly, the transfected T-47D and SK-BR-3 cells were harvested by trypsin digestion and plated into 96-well plates pre-coated with $50 \mu \mathrm{l}$ of $10 \mu \mathrm{g} / \mathrm{ml}$ type I collagen (BD Biosciences) at a density of $5 \times 10^{3}$ cells/well. Following culture for $1 \mathrm{~h}$ at $37^{\circ} \mathrm{C}$, the culture medium was removed, and the wells were carefully rinsed with PBS to remove the non-adherent cells. Subsequently, the remaining cells were added $10 \mu \mathrm{l} /$ well MTT solution (Roche) for $4 \mathrm{~h}$ incubation at $37^{\circ} \mathrm{C}$. Finally, the absorbance at $570 \mathrm{~nm}$ was recorded using a microplate reader. The relative cell adhesive ability normalized to that of the control group was used for statistical analysis.

Wound healing assay. The transfected T-47D and SK-BR-3 cells were harvested, seeded in 12 -well plates $\left(1 \times 10^{5}\right.$ cells/well $)$ and cultured in a $5 \% \mathrm{CO}_{2}$ atmosphere at $37^{\circ} \mathrm{C}$ for $12 \mathrm{~h}$. Subsequently, a wound was produced in the cell monolayer with the sterile tip of a $200-\mu 1$ pipette when the cell confluence was $>90 \%$, and the floating cells were rinsed with PBS. The cells were cultured in serum-free medium at $37^{\circ} \mathrm{C}$ with $5 \% \mathrm{CO}_{2}$ for $24 \mathrm{~h}$. Images were captured at 0 and $24 \mathrm{~h}$ using an inverted light microscope with a camera (magnification, $\mathrm{x} 100$ ). ImageJ version 1.49 software (National Institutes of Health) was used to analyze the wound width. The migratory rate of the cells was calculated as follows: Migratory rate $(\%)=\left(\mathrm{W}_{0 \mathrm{~h}}-\mathrm{W}_{24 \mathrm{~h}}\right) / \mathrm{W}_{0 \mathrm{~h}} \times 100 \%$, where $\mathrm{W}$ is the width of the wound at each time point.

Bioinformatics analysis. TargetScan 7.1 (http://www. targetscan.org/vert_71/) and miRWalk (http://mirwalk.umm. uni-heidelberg.de/) were employed to predict the target genes 
of miR-1298-5p. The common target genes between the two databases were overlapped using Venny 2.1.0 (https://bioinfogp.cnb.csic.es/tools/venny/) and uploaded to the STRING database (https://string-db.org/) for further analyses. UALCAN (http://ualcan.path.uab.edu/index.html) was used to assess the expression levels of the screened genes in breast invasive carcinoma cells according to the data from The Cancer Genome Atlas (TCGA) database. The 5-year prognosis of BC was analyzed using the Kaplan-Meier plotter (http://kmplot. com/analysis/) to further identify the key genes.

Luciferase reporter assay. The wild-type (Wt) 3'untranslated region (UTR) of E2F1 was amplified and subcloned into the psiCHECK $^{\mathrm{TM}}-2$ plasmid (Promega Corporation) between the sites of the restriction enzymes (XhoI and NotI) and the firefly luciferase coding sequence. The QuikChange II XL Site-Directed Mutagenesis kit (cat. no. 200521; Agilent Technologies, Inc.) was used to introduce mutations into the seed sequence of E2F1 to establish a mutated plasmid (Mut). The Lipofectamine 2000 Transfection Reagent was used to co-transfect the T-47D and SK-BR-3 cells with the psiCHECK $^{\mathrm{TM}}$ reporter vectors containing $400 \mathrm{ng} \mathrm{Wt}$ or Mut construct and $100 \mathrm{nM}$ miR-1298-5p mimics or the mimic-NC. After a transfection period of $48 \mathrm{~h}$, the culture medium was collected, and the luciferase activity was assayed using a Dual-Luciferase Reporter Assay system (Promega Corporation). The relative luciferase activity was calculated by normalizing the luminescence intensity of the firefly luciferase activity to that of the Renilla luciferase activity.

Western blot assay. The proteins from T47D and SKBR3 cells were extracted at $48 \mathrm{~h}$ post-transfection using the RIPA lysis buffer (Beyotime Institute of Biotechnology), and the protein concentration was determined using the Pierce BCA Protein Assay kit (Thermo Fisher Scientific, Inc.). The proteins $(40 \mu \mathrm{g} / \mathrm{lane})$ was separated by $10 \%$ SDS-PAGE and transferred to a PVDF membrane (MilliporeSigma). The membrane was blocked with 5\% BSA for $2 \mathrm{~h}$ at room temperature and incubated overnight at $4^{\circ} \mathrm{C}$ for immunoblotting with the primary rabbit polyclonal anti-E2F1 (cat. no. ab137415), rabbit monoclonal anti-E-cadherin (cat. no. ab76319), rabbit monoclonal anti-vimentin (cat. no. ab92547) and rabbit monoclonal anti-GAPDH (cat. no. ab181602) (all 1:1,000; all Abcam). Subsequently, the membranes were washed with TBST containing $0.05 \%$ Tween-20, and a HRP-conjugated goat anti-rabbit IgG H\&L secondary antibody (1:5,000; cat. no. ab6721; Abcam) was added and incubated for $2 \mathrm{~h}$ at room temperature. The blots were visualized using an enhanced chemiluminescence kit (Thermo Fisher Scientific, Inc.). GAPDH served as the reference control. Densitometry was conducted using ImageJ 1.8.0 (National Institutes of Health)

Statistical analysis. Data are presented as the mean \pm SD. Statistical analysis was performed using GraphPad Prism 8.0 (GraphPad Software, Inc.). Paired Student's t-test and one-way or two-way ANOVA with Tukey's post hoc test were applied to compare the statistical differences between variables. The correlation between miR-1298-5p and E2F1 was analyzed by Pearson's correlation analysis. In each experiment, three biological repeats were performed. $\mathrm{P}<0.05$ was considered to indicate a statistically significant difference.

\section{Results}

miR-1298-5p is expressed at low levels in the BC tissues and cells. The potential role of miR-1298-5p in BC was assessed using RT-qPCR in order to detect the expression levels of miR-1298-5p in the BC and normal breast tissues. The results demonstrated that the expression levels of miR-1298-5p were downregulated by $60 \%$ in $\mathrm{BC}$ tissues compared with those in the normal breast tissues (Fig. 1A). In addition, the expression levels of miR-1298-5p were decreased in the human BC cell lines T-47D, SK-BR-3, MDA-MB-231, MCF7 and BT-474 compared with those in the normal breast cell line MCF10A (Fig. 1B). To further analyze the association between miR-1298-5p and BC, the miR-1298-5p mimic and inhibitor were designed and transfected into T-47D and SK-BR-3 BC cells. RT-qPCR analysis revealed a 3.2-fold increase in the expression levels of miR-1298-5p in the mimic group and a 0.7 -fold decrease in the inhibitor group compared with those in the control groups, indicating high transfection efficiency (Fig. 1C). Since the effects of co-transfection with mimic-NC and inhibitor-NC were similar to those of single NC transfections, the co-transfection of mimic-NC and inhibitor-NC was used as the control for the subsequent experiments. Overall, these results suggested that miR-1298-5p expression was reduced in the $\mathrm{BC}$.

Effects of miR-1298-5p in BC progression. The present study further investigated the function of miR-1298-5p in the tumorigenesis of $\mathrm{BC}$ by detecting the viability and proliferative ability of T-47D and SK-BR-3 cells transfected with the miR-1298-5p mimic, inhibitor or NC. The results of the CCK-8 assay demonstrated that BC cells transfected with the miR-1298-5p mimic exhibited a decline in the cell viability following culture for 3 and 4 days compared with that in the control group; however, the viability of the two BC cell lines was significantly enhanced following transfection with the miR-1298-5p inhibitor (Fig. 2A). Similarly, the BrdU assay revealed a 0.4-fold reduction in the DNA synthesis levels in the T-47D and SK-BR-3 cells transfected with the miR-1298-5p mimic and a 1.5-1.8-fold increase in the DNA synthesis in the cells transfected with the miR-1298-5p inhibitor compared with those in the control groups (Fig. 2B). These results suggested that miR-1298-5p suppressed the ability of the BC cells to proliferate. Furthermore, the results of the caspase-3 activity assay demonstrated that the BC cell lines transfected with the miR-1298-5p mimic displayed a 3-fold increase in the caspase- 3 activity compared with that in the control groups, whereas the inhibition of miR-1298-5p reduced the caspase-3 activity by 0.5 -fold (Fig. 2C). In addition, the changes in the apoptotic rate were detected by flow cytometry, and the results were similar to those observed in the caspase-3 activity assay; the miR-1298-5p mimics increased, whereas inhibition of miR-1298-5p reduced the apoptotic rate compared with that observed in the control groups (Fig. 2D). These results demonstrated the promotive effect of miR-1298-5p on BC cell apoptosis. Subsequently, the cell adhesion and wound healing assays were performed to evaluate the effects of miR-1298-5p 
A

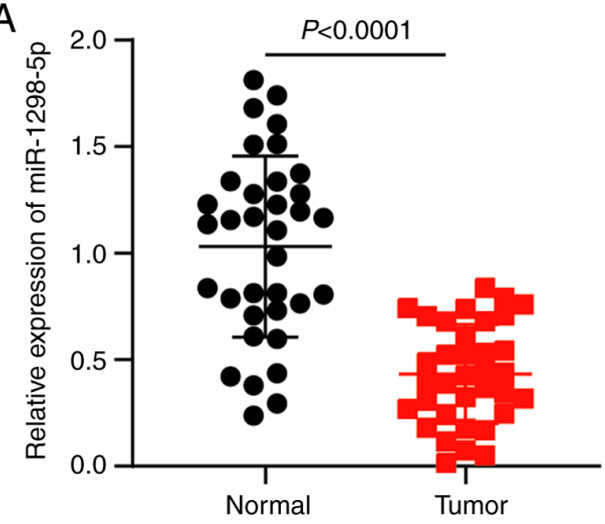

C

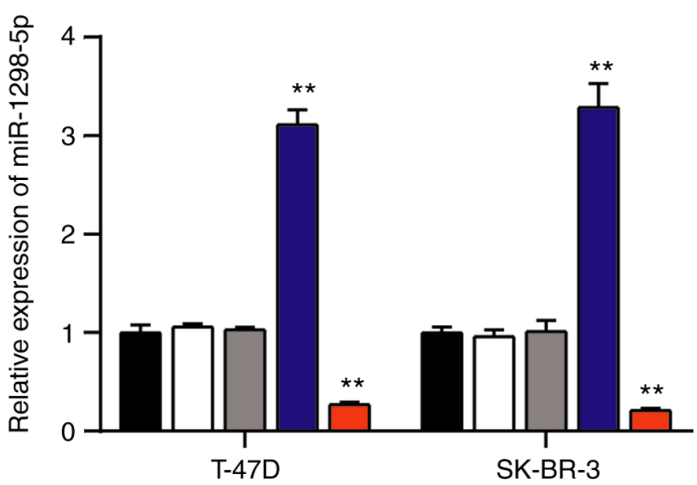

$\mathrm{B}$

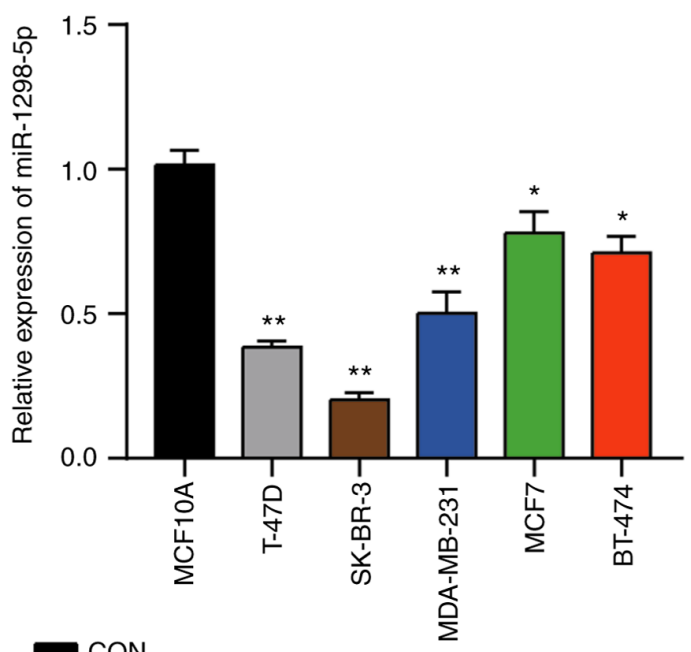

$\square$ CON

$\square$ Mimic-NC

$\square$ Inhibitor-NC

$\square$ Mimic

$\square$ Inhibitor

Figure 1. miR-1298-5p is expressed at low levels in breast cancer tissues and cells. (A) RT-qPCR analysis of relative miR-1298-5p expression levels in breast cancer and normal breast tissues. (B) RT-qPCR analysis of relative miR-1298-5p expression levels in breast cancer cell lines T-47D, SK-BR-3, MDA-MB-231, MCF7 and BT-474 and a normal breast cell line MCF10A. (C) RT-qPCR analysis of miR-1298-5p expression in T-47D and SK-BR-3 cell lines following transfection with miR-1298-5p mimics or inhibitor. Data are presented as the mean \pm SD and were analyzed by Student's t-test or one-way ANOVA. ${ }^{*} \mathrm{P}<0.05$ and ${ }^{* *} \mathrm{P}<0.001$ vs. MCF10A or CON. miR, microRNA; RT-qPCR, reverse transcription-quantitative PCR; CON, blank control; NC, negative control.

on the adhesive capacity of $\mathrm{BC}$ cells. The results of the cell adhesion assay revealed that the percentage of adherent T-47D and SK-BR-3 cells exhibited a 0.4 -fold reduction in the miR-1298-5p mimic group and a 1.4-fold increase in the miR-1298-5p inhibitor group compared with that in the control group (Fig. 3A). Western blot assay evaluated the protein expression levels of vimentin and E-cadherin, which are associated with cell adhesion (37). The results of this assay demonstrated that the protein expression levels of vimentin in the miR-1298-5p mimic group decreased, whereas those of E-cadherin increased compared with those in the control group. The effects of the miR-1298-5p inhibitor on the protein expression levels of vimentin and E-cadherin were opposite to those in the mimic group (Fig. 3B). In addition, according to the results of the wound healing assay, the migratory rate of T-47D and SK-BR-3 cells was reduced in the miR-1298-5p mimic group and increased in the miR-1298-5p inhibitor group compared with that in the control groups (Fig. 3C). Taken together, these results suggested that miR-1298-5p inhibited the proliferation, adhesion and migration of $\mathrm{BC}$ cells and induced apoptosis.

E2F1 is a target gene of miR-1298-5p in BC cells. TargetScan and miRWalk databases were used to predict the potential target genes of miR-1298-5p. Following Venny 2.1.0 analysis, a total of 125 target genes overlapped between the
miRWalk and TargetScan results (Fig. 4A). These genes were further analyzed using the STRING database, and 15 key genes involved in 'regulation of cellular biosynthetic process', 'cellular metabolic process' and 'positive regulation of cellular process' were discovered (Fig. 4B). Among these genes, higher expression levels of E2F1 were observed in breast carcinoma samples in TCGA database (Fig. 4C). The Kaplan-Meier plotter analysis demonstrated that high expression levels of E2F1 were associated with a poor prognosis of BC (Fig. 4D). Therefore, E2F1 was selected as the gene of interest for further analysis. In addition, the TargetScan results revealed that the E2F1 3'UTR contained a putative recognition sequence (GAAUGAA) targeted by miR-1298-5p (Fig. 4E). To assess the ability of miR-1298-5p to directly target the 3'UTR of E2F1, the luciferase activity assay was performed. Following transfection with the miR-1298-5p mimic, the luciferase activity of T-47D and SK-BR-3 cells containing the Wt construct decreased by 0.6 -fold compared with that in the cells-transfected with the mimic-NC. However, the luciferase activity of the T-47D and SK-BR-3 cells transfected with the Mut construct was not affected by the miR-1298-5p mimic (Fig. 4F). Furthermore, the expression levels of E2F1 were significantly upregulated in the breast tumor tissues compared with those in normal breast tissues (Fig. 4G). In addition, the expression levels of E2F1 were negatively correlated with those of miR-1298-5p in the breast tumor tissues (Fig. 4H). 

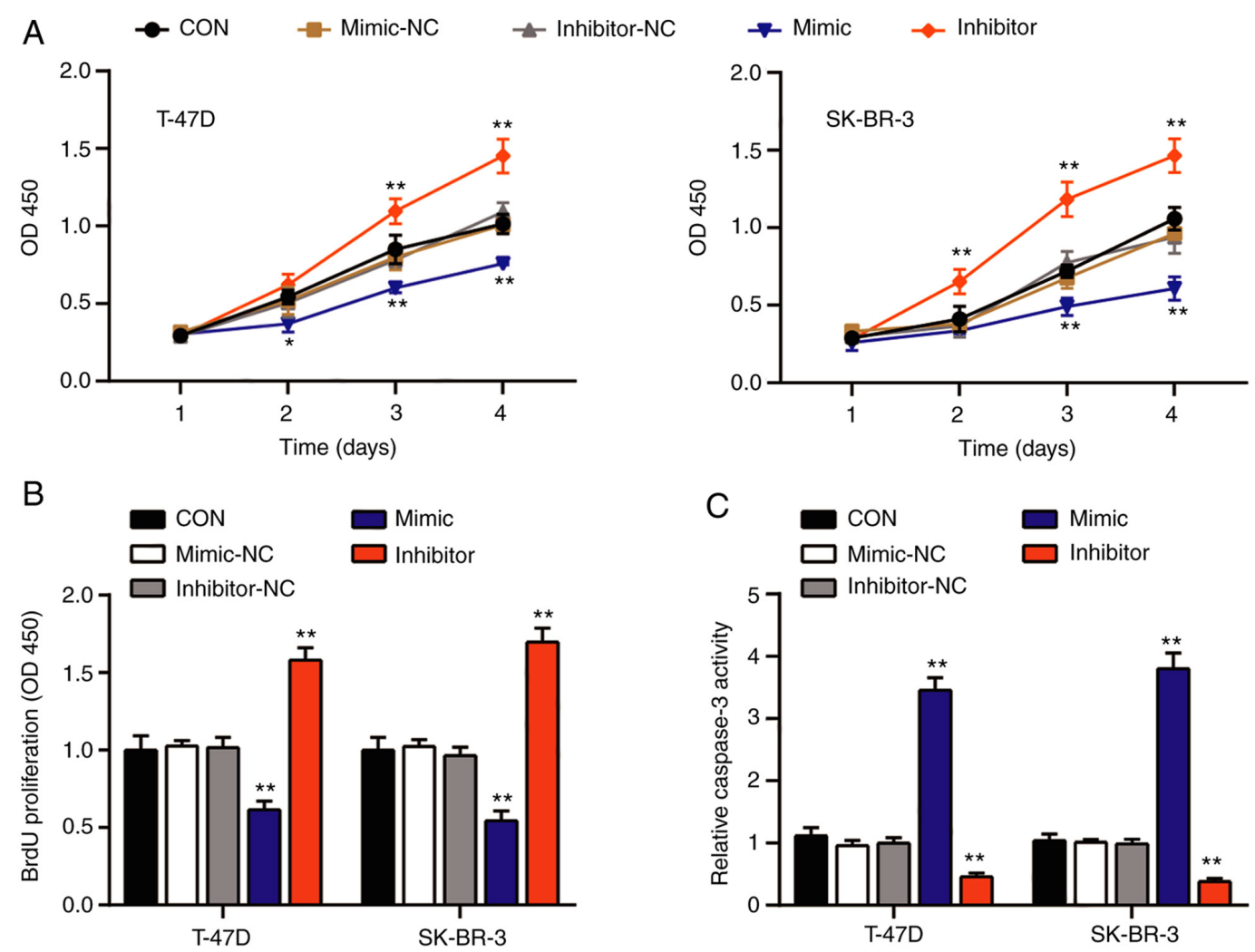

D
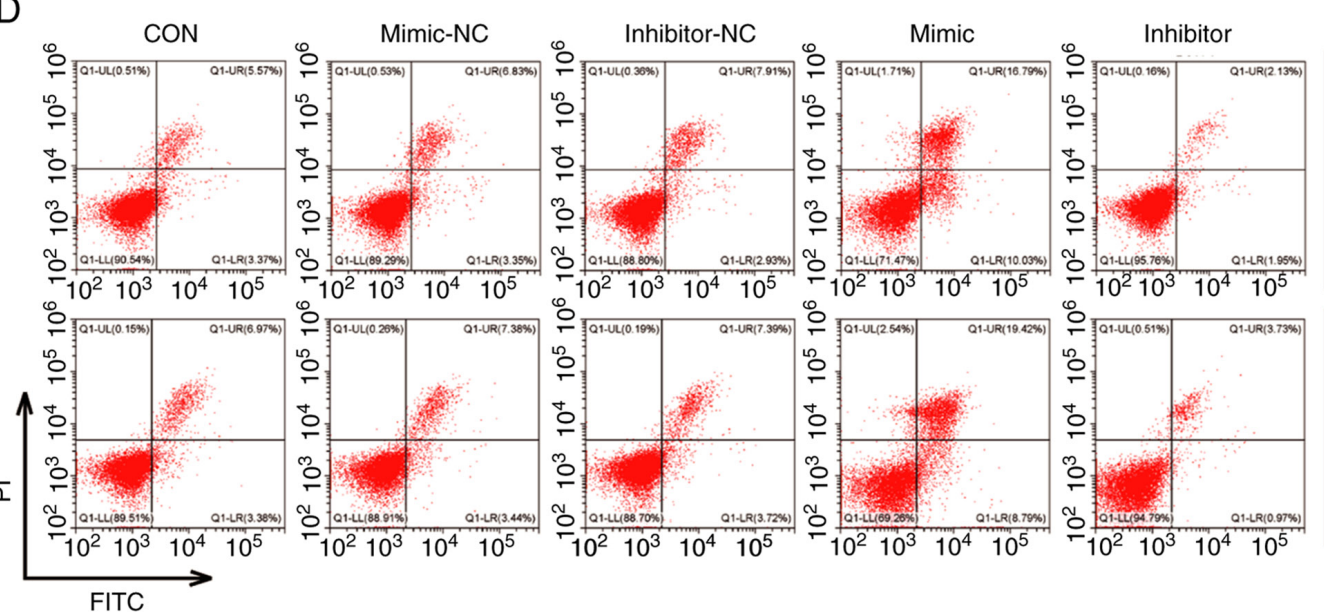

$\underset{⿱}{\stackrel{0}{f}}$
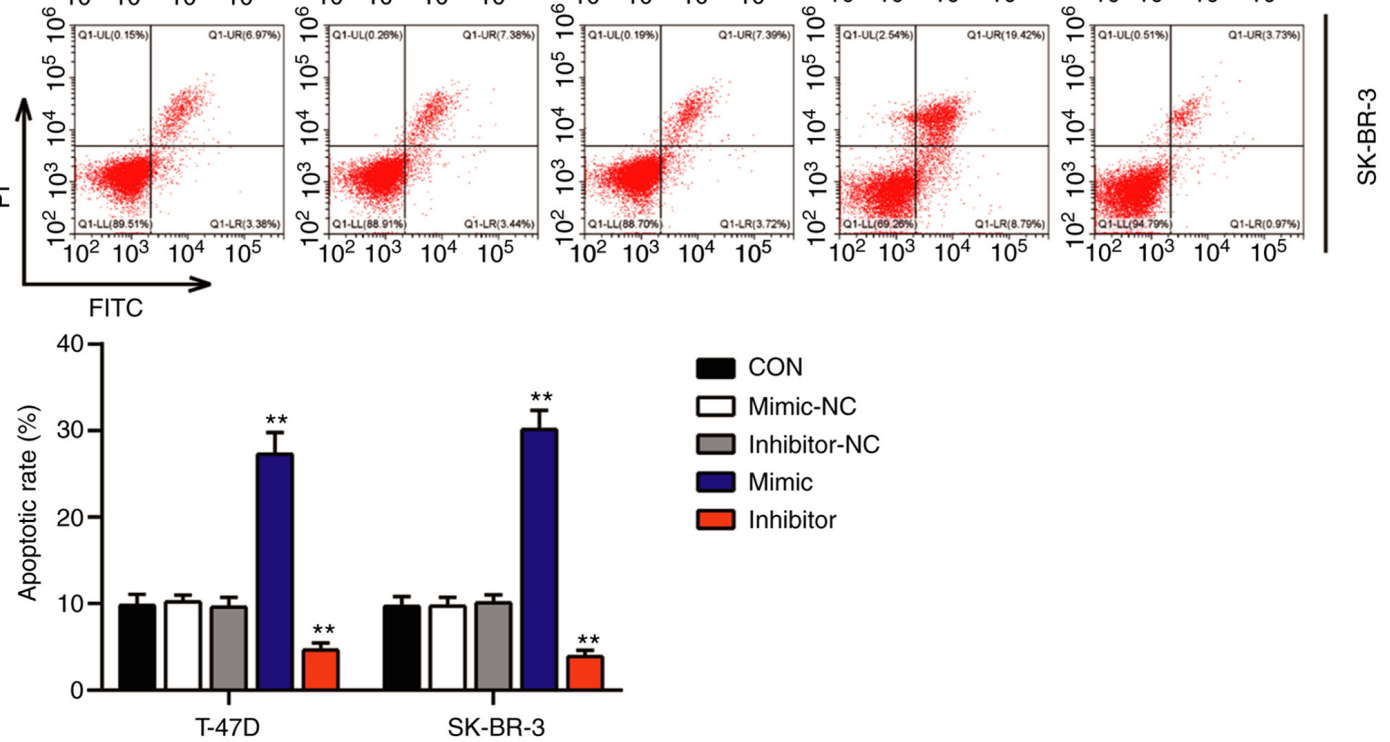

Figure 2. miR-1298-5p accelerates breast cancer cell proliferation and inhibits apoptosis. (A) The viability of transfected T-47D and SK-BR-3 cells following culture for 1-4 days by was assessed by the Cell Counting Kit-8 assay. (B) BrdU assay-based proliferation analysis of transfected T-47D and SK-BR-3 cells (C) Caspase-3 activity assay was performed to evaluate the apoptotic rate of transfected T-47D and SK-BR-3 cells. (D) The apoptotic rate of transfected T-47D and SK-BR-3 cells was analyzed by flow cytometry. Data are presented as the mean \pm SD and were analyzed by one- or two-way ANOVA. "P $<0.05$ and ${ }^{* *} \mathrm{P}<0.001$ vs. CON. miR, microRNA; CON, blank control; NC, negative control; OD, optical density; BrdU, 5-bromo-2'-deoxyuridine; PI, propidium iodide.

These results demonstrated that $\mathrm{E} 2 \mathrm{~F} 1$ was a direct target of miR-1298-5p in BC cells.
miR-1298-5p targets E2F1 to affect BC cell malignant behaviors. To test whether miR-1298-5p regulated the proliferation, 


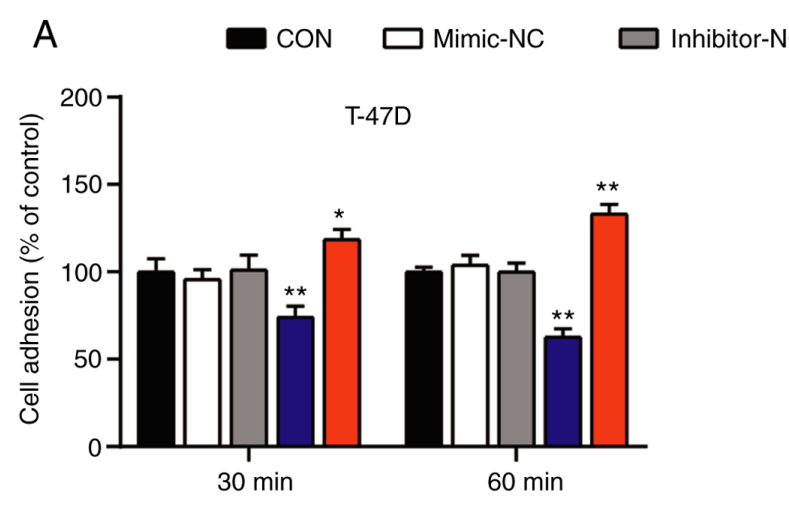

B
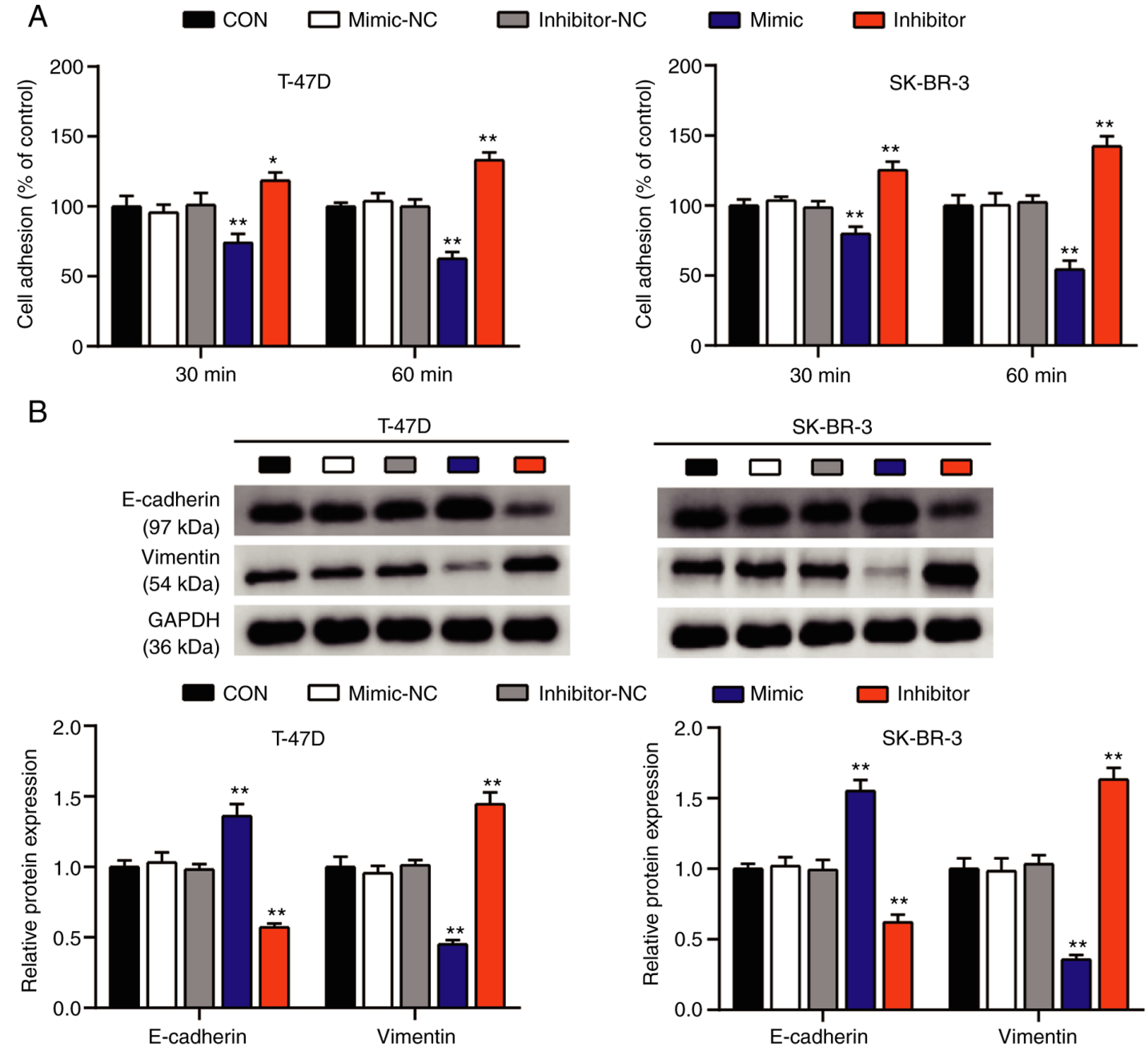

C
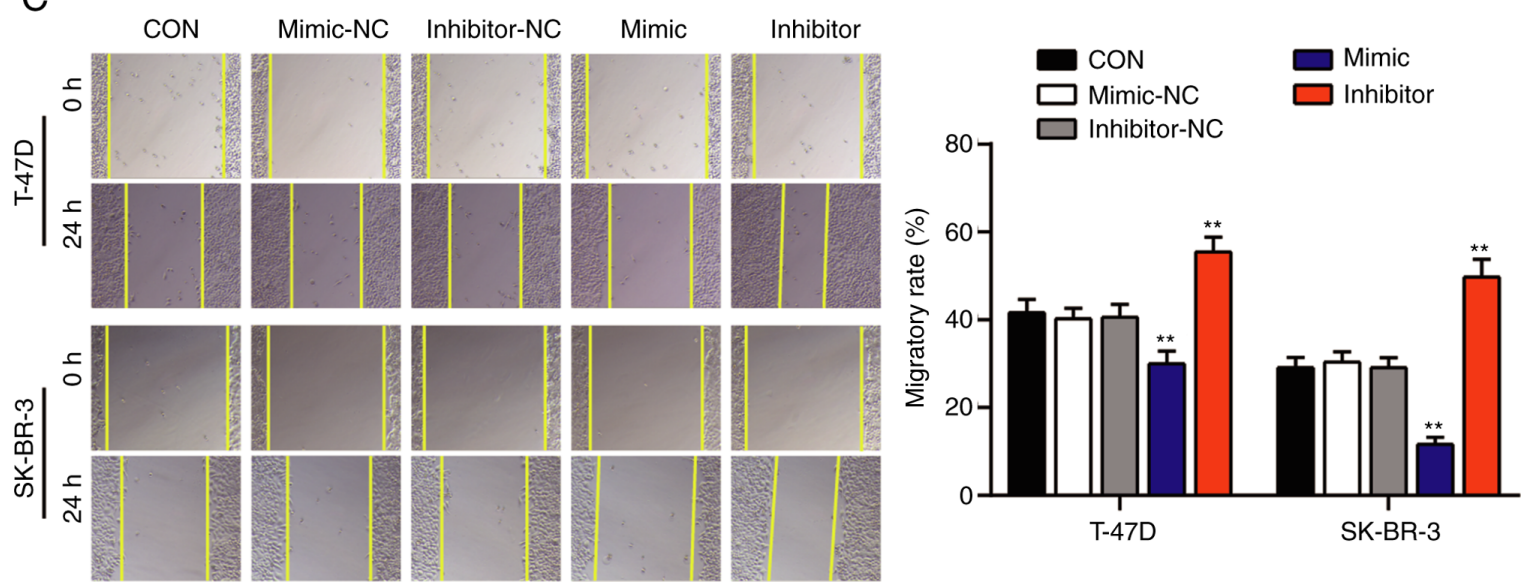

Figure 3. miR-1298-5p accelerates breast cancer cell adhesion and migration. (A) The adhesive ability of transfected T-47D and SK-BR-3 cells was analyzed following culture for 30 and 60 min by cell adhesion assay. (B) Western blot assay was performed to evaluate the protein expression levels of vimentin and E-cadherin. (C) Wound healing assay was used for the analysis of the migratory capacity of transfected T-47D and SK-BR-3 cells. Data are presented as the mean \pm SD and were analyzed by one- or two-way ANOVA. ${ }^{*} \mathrm{P}<0.05$ and ${ }^{* *} \mathrm{P}<0.001$ vs. CON. miR, microRNA; CON, blank control; NC, negative control.

adhesion, migration and apoptosis by targeting E2F1 in BC cells, T-47D and SK-BR-3 cell lines were transfected with the E2F1 siRNA and the miR-1298-5p inhibitor separately or together. The results of RT-qPCR and western blot analyses demonstrated that the mRNA and the protein levels of E2F1 were downregulated by $\sim 0.5$-fold in the T47D and SKBR3 cells transfected with the E2F1 siRNA compared with those in the control groups (Fig. 5A and B). However, the expression levels of the E2F1 mRNA and protein increased in the two BC cell lines following transfection with the miR-1298-5p inhibitor compared with those in the control group. The cells co-transfected with the E2F1 siRNA and the miR-1298-5p inhibitor exhibited no significant changes in the E2F1 expression levels compared with those in the control group, indicating that these two molecules may 
A

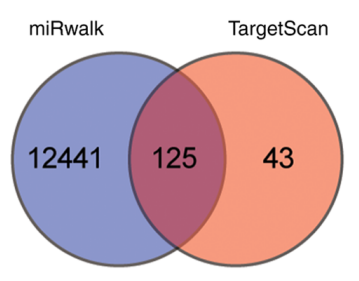

B

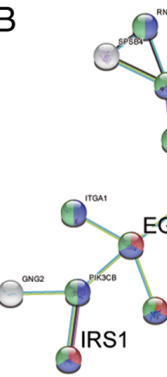

USP47

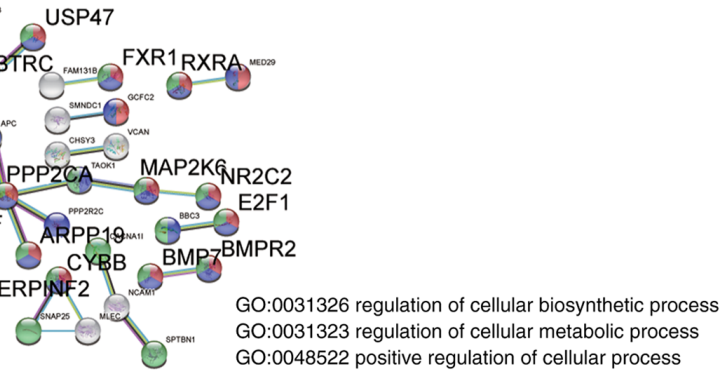

C

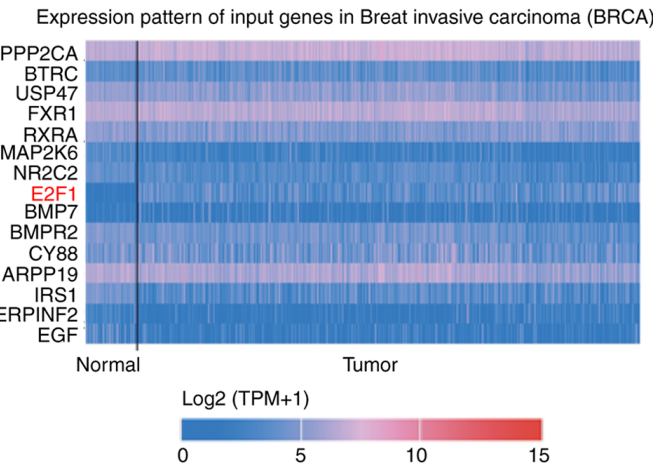

D

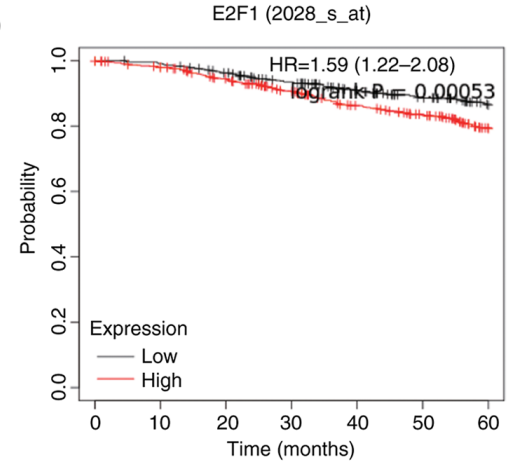

Number at risk

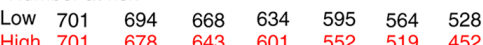

High $\begin{array}{lllllll}701 & 678 & 643 & 601 & 552 & 519 & 452\end{array}$

E

Position 283-289 of wild-type E2F1 3' UTR $\quad 5^{\prime}$...UGUGCAUGUACCGGGGAAUGAAG.

hsa-miR-1298-5p 3' AUGUAGACCUGUCGGCUUACUU

Position 283-289 of mutant E2F1 3' UTR $\quad 5^{\prime}$...UGUGCAUGUACCGGGCUUACUUG.

$\mathrm{F}$

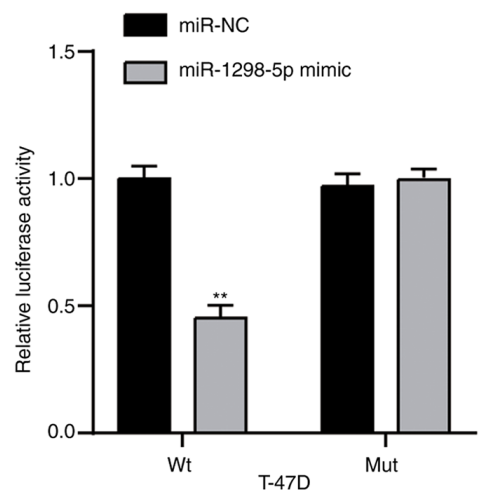

G

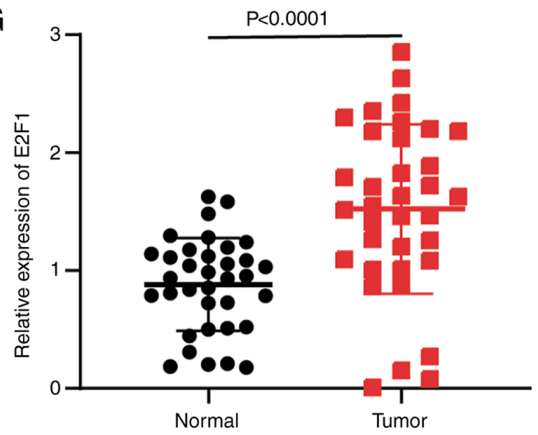

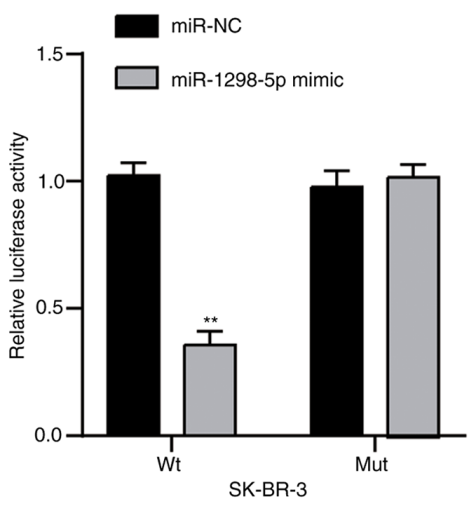

$\mathrm{H}$

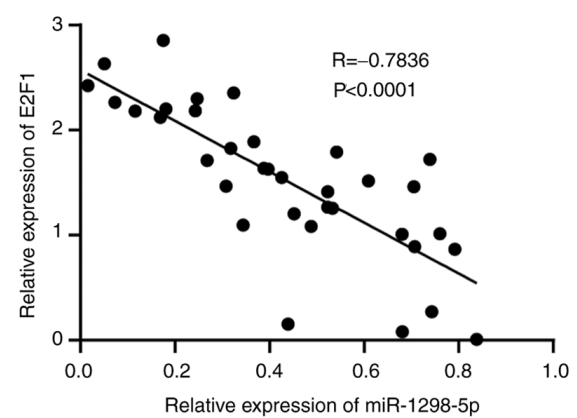

Figure 4. E2F1 is a target gene of miR-1298-5p in breast cancer cells. (A) A total of 125 target genes of miR-1295-5p overlapped between the miRwalk and TargetScan database search results. (B) A total of 15 key genes were identified to participate in three key cellular processes by STRING analysis. (C) E2F1 was upregulated in breast invasive carcinoma samples in The Cancer Genome Atlas database. (D) High levels of E2F1 expression were associated with a poor prognosis. (E) A miR-1298-5p binding site on the 3'UTR of E2F1 mRNA was predicted using TargetScan. (F) Luciferase activity assay in T-47D and SK-BR-3 cells co-transfected with miR-1298-5p mimics or NC and luciferase reporter plasmids containing Wt or Mut miR-1298-5p binding site on E2F1 3'UTR. (G) Reverse transcription-quantitative PCR analysis of the relative E2F1 expression levels in breast cancer and normal breast tissues. (H) Pearson's correlation analysis of the expression levels of miR-1298-5p and E2F1 in breast cancer tissues. Data are presented as the mean \pm SD and were analyzed by Student's t-test. "* P<0.001. miR, microRNA; E2F1, E2F transcription factor 1; GO, Gene Ontology; NC, negative control; UTR, untranslated region; Wt, wild-type; Mut, mutant; TPM, transcripts per million. 

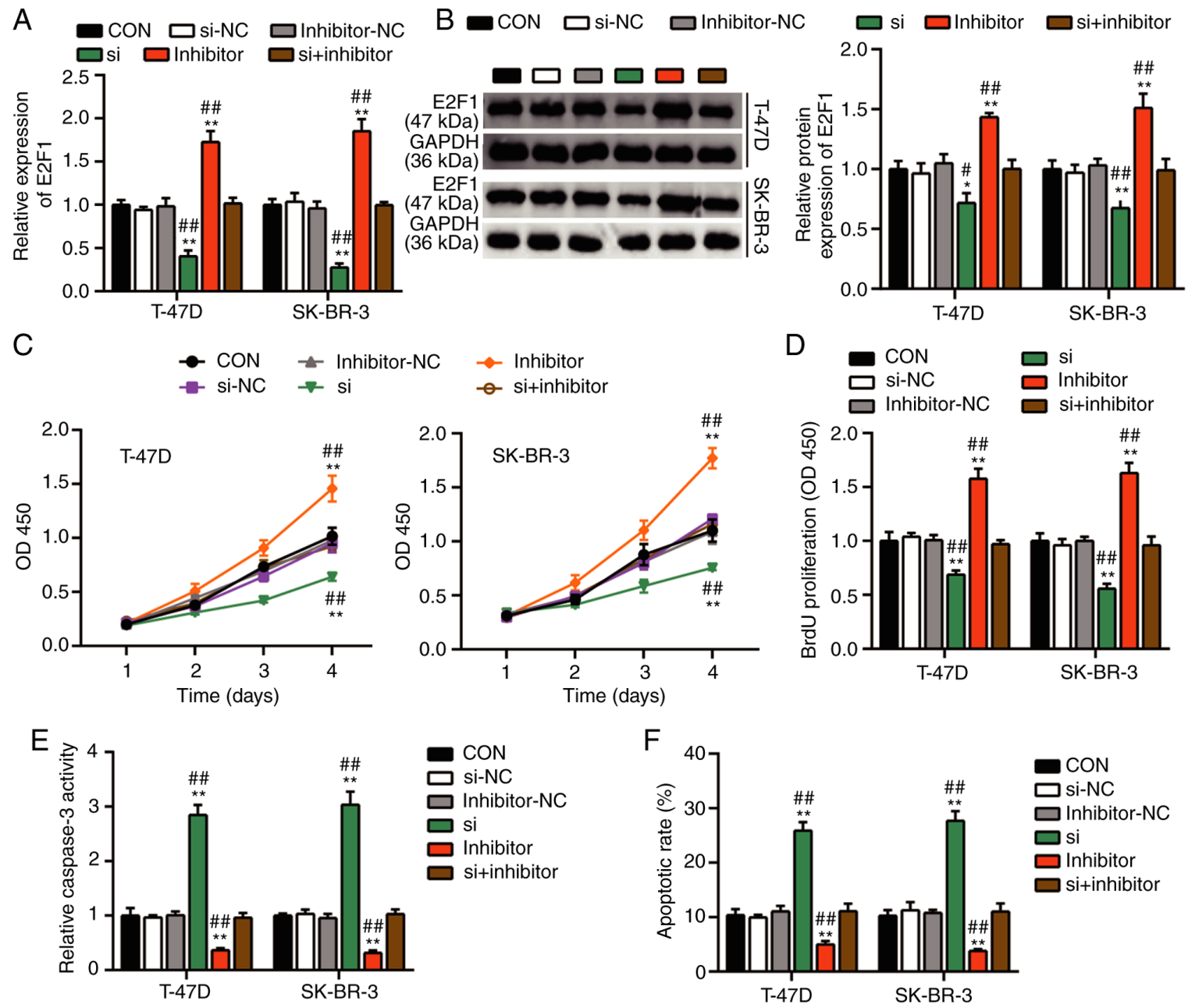

G

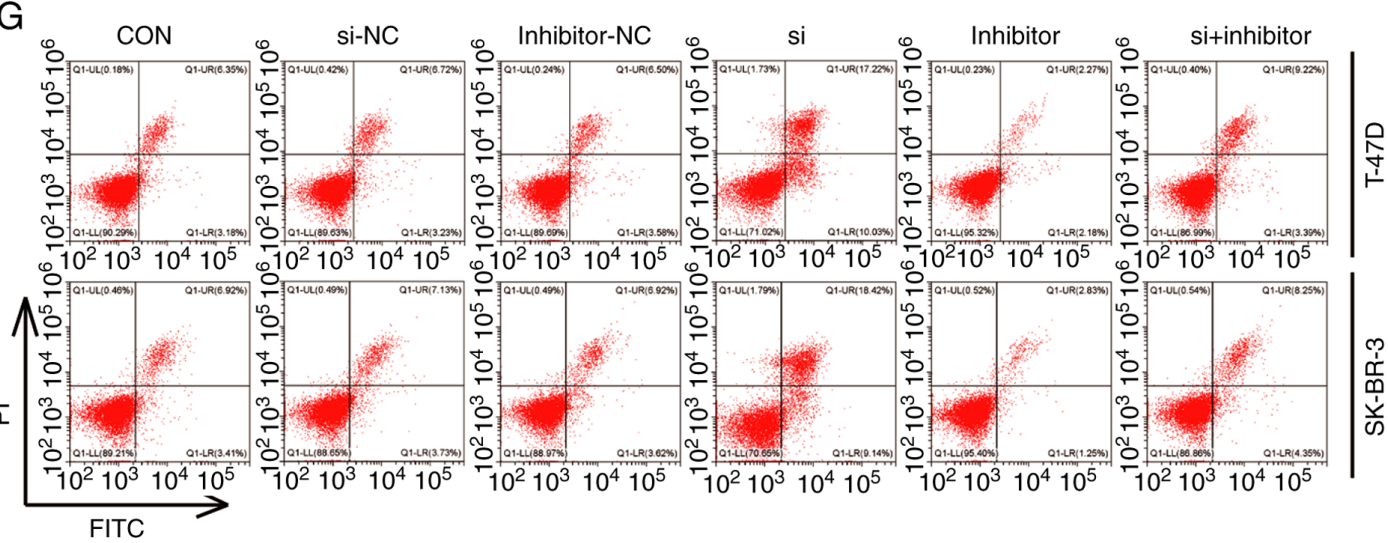

Figure 5. miR-1298-5p promotes breast cancer cell proliferation and represses apoptosis by downregulating E2F1. (A) Reverse transcription-quantitative PCR analysis of E2F1 expression levels in transfected T-47D and SK-BR-3 cell lines. (B) Western blot analysis of E2F1 protein expression levels in transfected T-47D and SK-BR-3 cells. (C) The viability of transfected T-47D and SK-BR-3 cells was analyzed following culture for 1,2,3 and 4 days by Cell Counting Kit-8 assay. (D) BrdU assay-based proliferation analysis of transfected T-47D and SK-BR-3 cells. (E) Caspase-3 activity assay was performed to evaluate the apoptotic rate of transfected T-47D and SK-BR-3 cells. (F and G) The apoptotic rate of transfected T-47D and SK-BR-3 cells was analyzed by flow cytometry assay. Data are presented as the mean $\pm \mathrm{SD}$ and were analyzed by one- or two-way ANOVA. ${ }^{*} \mathrm{P}<0.05$ and ${ }^{* *} \mathrm{P}<0.001$ vs. CON; ${ }^{*} \mathrm{P}<0.05$ and ${ }^{\# \#} \mathrm{P}<0.001$ vs. si + inhibitor. miR, microRNA; E2F1, E2F transcription factor 1; CON, blank control; NC, negative control; si, small interfering RNA targeting E2F1; OD, optical density; BrdU, 5-bromo-2'-deoxyuridine; PI, propidium iodide.

offset each other (Fig. 5A and B). The results of further experiments also demonstrated that the silencing of E2F1 reduced the viability and proliferative capacity of T-47D and SK-BR-3 cells compared with those in the control groups. However, the inhibition of miR-1298-5p reversed this effect (Fig. 5C and D). In addition, the silencing of E2F1 increased the caspase-3 activity levels of T-47D and SK-BR-3 cells by $\sim 3$-fold compared with those in the control groups. However, no significant changes were observed in the cells co-transfected with the E2F1 siRNA and miR-1298-5p inhibitor (Fig. 5E). Similarly, the apoptotic rates of T-47D and SK-BR-3 cells increased after silencing E2F1 compared with those in the control groups, whereas no 


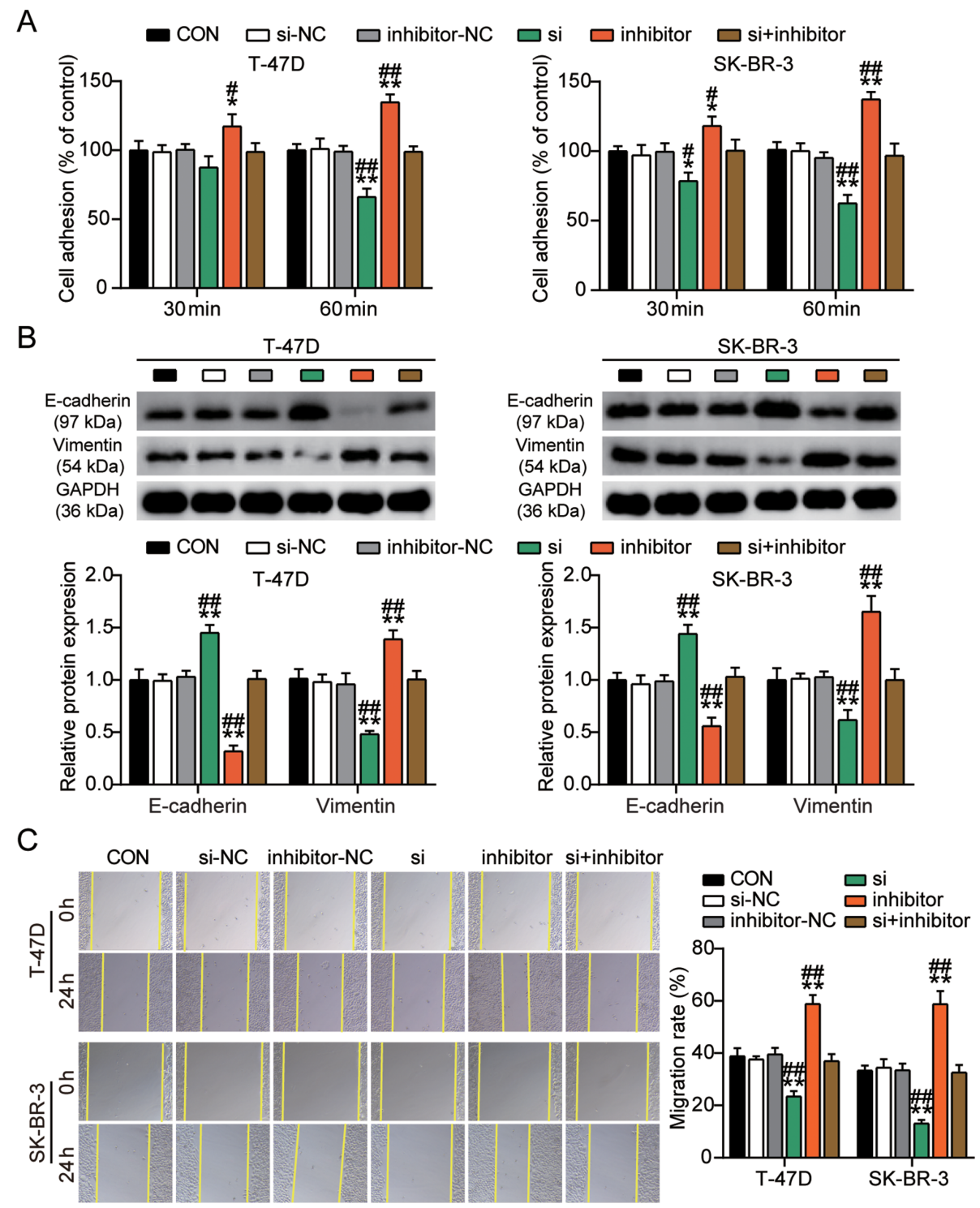

Figure 6. miR-1298-5p promotes breast cancer cell adhesion and migration by targeting E2F1. (A) The adhesive ability of transfected T-47D and SK-BR-3 cells was analyzed following 30 and $60 \mathrm{~min}$ of culture by cell adhesion assay. (B) Western blot assay was performed to evaluate the protein expression levels of vimentin and E-cadherin. (C) Wound healing assay was used to determine the migratory capacity of transfected T-47D and SK-BR-3 cells. Data are presented as the mean \pm SD and were analyzed by one- or two-way ANOVA. ${ }^{*} \mathrm{P}<0.05$ and ${ }^{* *} \mathrm{P}<0.001$ vs. CON; ${ }^{*} \mathrm{P}<0.05$ and ${ }^{\# \#} \mathrm{P}<0.001$ vs. si + inhibitor. miR, microRNA; E2F1, E2F transcription factor 1; CON, blank control; NC, negative control; si, small interfering RNA targeting E2F1.

significant changes were present in the cells co-transfected with the E2F1 siRNA and miR-1298-5p inhibitor (Fig. 5F). In addition, the results of the cell adhesion assay demonstrated that the adhesive ability of T-47D and SK-BR-3 cells was significantly inhibited when E2F1 was silenced; however, the miR-1298-5p inhibitor reversed this effect (Fig. 6A). Western blotting results revealed that following $\mathrm{E} 2 \mathrm{~F} 1$ interference, the protein expression levels of vimentin decreased, whereas the levels of E-cadherin increased compared with those in the control groups. However, co-transfection with si-E2F1 and the miR-1298-5p inhibitor reversed the effects of si-E2F1 on the expression of vimentin and E-cadherin in T-47D and SK-BR-3 cells (Fig. 6B). In the cell migration assay, the silencing of E2F1 inhibited cell migration compared with that in the control group, and this inhibitory effect was reversed by co-transfection with the miR-1298-5p inhibitor (Fig. 6C). Taken together, these results suggested that by targeting E2F1, miR-1298-5p exerted not only suppressive effects on the proliferation, adhesion and migration of $\mathrm{BC}$ cells, but also promotive effects on $\mathrm{BC}$ cell apoptosis.

\section{Discussion}

Numerous studies have reported that miRNAs regulate the tumorigenesis and metastasis of $\mathrm{BC}$ by targeting genes associated with cancer progression $(8,38)$ such as miR-106b-5p targeting CNN1 in breast cancer (39), miR-944 targeting MACC1 in colorectal cancer (40) and miR-548c targeting Twist in ovarian cancer (41). In BC, miR-1298 has been demonstrated to inhibit malignant cell behaviors by targeting ADAM9 (18). In contrast to the aforementioned study, the results of the present study demonstrated that miR-1298-5p targeted E2F1 and negatively affected the proliferation, adhesion, migration and apoptosis of BC cells. These results may be instrumental in developing a potential strategy to repress the tumorigenesis of BC. In addition, 
the results of the present study revealed that the expression levels of miR-1298-5p were aberrantly downregulated in BC tissues and cells compared with those in normal breast tissues and cells, respectively. This result was in agreement with previous studies that described the participation of $\mathrm{miR}-1298-5 \mathrm{p}$ in regulating the progression of gastric, bladder and lung cancer $(15,17,42)$. Cell proliferation, adhesion, migration and apoptosis are widely used to determine the tumorigenic and metastatic potential of cancer cells $(43,44)$. The effects of miR-1298-5p on cell proliferation, adhesion, migration and apoptosis were evaluated in the current study, and the results demonstrated that miR-1298-5p suppressed the tumorigenic capacity of BC. These results were similar and consistent with previous reports on the effect of miR-1298-5p in other cancer types $(15,17,42)$. Thus, the present study validated the tumor-suppressive role of miR-1298-5p in cancer development.

The present study also aimed to determine the molecular mechanism underlying the regulation of $\mathrm{BC}$ cell behaviors by miR-1298-5p. Solomon et al (35) predicted the targeting relationship between miR-1298-5p and E2F1 by bioinformatics analysis in human myeloma cells, but did not validate this association by functional cell experiments. Following target scanning and bioinformatics analysis, the present study identified E2F1 as a potential target of miR-1298-5p; this was consistent with the aforementioned study. Notably, the results of the present study demonstrated that E2F1 levels were upregulated in $\mathrm{BC}$ tissues compared with those in normal breast tissues, and they were negatively correlated with the expression levels of miR-1298-5p in BC. The luciferase activity assay demonstrated that E2F1 was a direct target of miR-1298-5p in BC cells. In addition, the results of the functional assays suggested that by inhibiting E2F1 expression, miR-1298-5p exerted its repressive role in the proliferation, adhesion and migration of BC cells and its promotive role in apoptosis. Previous studies have reported E2F1 as a key regulator in the tumorigenesis of various types of cancer, including BC $(24,29,45)$. Both oncogenic and tumor-suppressive functions of E2F1 have been demonstrated in BC cells (30,31). The results of the present study revealed that $\mathrm{E} 2 \mathrm{~F} 1$ may act as an oncogene and contribute to the pathogenesis of $\mathrm{BC}$.

Despite the aforementioned results, the signaling pathway downstream of the miR-1298-5p/E2F1 axis that may regulate the aggressiveness of breast tumors was not explored in the present study. As a regulator of the cell cycle, E2F1 directly promotes the transcription of $\mathrm{P} 73$, which consecutively activates the proapoptotic target genes (p53 and CDKN2A) and induces apoptosis in $\mathrm{BC}$ and other types of cancer including cervical cancer, retinoblastoma and prostate cancer (46-50). The effects of the miR-1298-5p/E2F1 axis on BC cells were assessed under in vitro conditions in the current study. Therefore, in future research, it is pertinent to construct a BC animal model and verify these results under in vivo conditions. The serum levels of miR-1298-5p in patients with BC and healthy volunteers should also be measured to evaluate the potential value of miR-1298-5p in the diagnosis of BC. Furthermore, long non-coding RNAs (lncRNAs) have been recently demonstrated to affect BC progression (51). However, the lncRNA regulatory mechanism for miR-1298-5p has not been reported. In the future, the upstream regulation mechanism of miR-1298-5p in BC needs to be explored.
In conclusion, the results of the present study suggested that miR-1298-5p may affect BC progression by targeting E2F1. miR-1298-5p exerted not only suppressive effects on the proliferation, adhesion and migration of $\mathrm{BC}$ cells, but also promotive effects on $\mathrm{BC}$ cell apoptosis by targeting E2F1. These results may assist in providing new targets for the treatment and diagnosis of $\mathrm{BC}$.

\section{Acknowledgements}

Not applicable.

\section{Funding}

No funding was received.

\section{Availability of data and materials}

The datasets used and/or analyzed during the current study are available from the corresponding author on reasonable request.

\section{Authors' contributions}

DWH and ZMF designed the experiments, and confirm the authenticity of all the raw data. JZ and CYH conducted the experiments and wrote the manuscript. All authors read and approved the final manuscript.

\section{Ethics approval and consent to participate}

Ethic Committee of The First Bethune Hospital of Jilin University (Jilin, China) approved the study (approval no. 17K038-009). Written informed consent was obtained from all patients.

\section{Patient consent for publication}

Not applicable.

\section{Competing interests}

The authors declare that they have no competing interests.

\section{References}

1. Bray F, Ferlay J, Soerjomataram I, Siegel RL, Torre LA and Jemal A: Global cancer statistics 2018: GLOBOCAN estimates of incidence and mortality worldwide for 36 cancers in 185 countries. CA Cancer J Clin 68: 394-424, 2018.

2. Ferlay J, Colombet M, Soerjomataram I, Mathers C, Parkin DM, Piñeros M, Znaor A and Bray F: Estimating the global cancer incidence and mortality in 2018: GLOBOCAN sources and methods. Int J Cancer 144: 1941-1953, 2019.

3. DeSantis CE, Ma J, Gaudet MM, Newman LA, Miller KD, Goding Sauer A, Jemal A and Siegel RL: Breast cancer statistics, 2019. CA Cancer J Clin 69: 438-451, 2019.

4. Harbeck N and Gnant M: Breast cancer. Lancet 389: 1134-1150, 2017.

5. Bartel DP: MicroRNAs: Genomics, biogenesis, mechanism, and function. Cell 116: 281-297, 2004.

6 . Ebert MS and Sharp PA: Roles for microRNAs in conferring robustness to biological processes. Cell 149: 515-524, 2012.

7. Wozniak M, Mielczarek A and Czyz M: miRNAs in Melanoma: Tumor suppressors and oncogenes with prognostic potential. Curr Med Chem 23: 3136-3153, 2016. 
8. Ding L, Gu H, Xiong X, Ao H, Cao J, Lin W, Yu M, Lin J and Cui Q: MicroRNAs involved in carcinogenesis, prognosis, therapeutic resistance and applications in human triple-negative breast cancer. Cells 8: 1492, 2019

9. Calin GA and Croce CM: MicroRNA signatures in human cancers. Nat Rev Cancer 6: 857-866, 2006.

10. Liu H: MicroRNAs in breast cancer initiation and progression. Cell Mol Life Sci 69: 3587-3599, 2012.

11. Schwarzenbacher D, Klec C, Pasculli B, Cerk S, Rinner B, Karbiener M, Ivan C, Barbano R, Ling H, Wulf-Goldenberg A, et al: MiR-1287-5p inhibits triple negative breast cancer growth by interaction with phosphoinositide 3-kinase CB, thereby sensitizing cells for PI3Kinase inhibitors. Breast Cancer Res 21: 20, 2019.

12. Ying X, Sun Y and He P: MicroRNA-137 inhibits BMP7 to enhance the epithelial-mesenchymal transition of breast cancer cells. Oncotarget 8: 18348-18358, 2017.

13. Hu W, Wang M, Yin H, Yao C, He Q, Yin L, Zhang C, Li W, Chang $\mathrm{G}$ and Wang S: MicroRNA-1298 is regulated by DNA methylation and affects vascular smooth muscle cell function by targeting connexin 43. Cardiovasc Res 107: 534-545, 2015.

14. Xu X, Ban Y, Zhao Z, Pan Q and Zou J: MicroRNA-1298-3p inhibits proliferation and invasion of glioma cells by downregulating Nidogen-1. Aging (Albany NY) 12: 7761-7773, 2020

15. Du Z, Wu J, Wang J, Liang Y, Zhang S, Shang Z and Zuo W: MicroRNA-1298 is downregulated in non-small cell lung cancer and suppresses tumor progression in tumor cells. Diagn Pathol 14: 132, 2019

16. Xue G, Lin X, Wu JF, Pei D, Wang DM, Zhang J and Zhang WJ Identification of key genes of papillary thyroid carcinoma by integrated bioinformatics analysis. Biosci Rep 40: BSR20201555, 2020 .

17. Qiu ZK, Liu N, Zhao SF, Ding AP, Cheng G, Qiu WS and Qi WW: MiR-1298 expression correlates with prognosis and inhibits cell proliferation and invasion of gastric cancer. Eur Rev Med Pharmacol Sci 22: 1672-1679, 2018.

18. Chen W, Lu Q, Li S, Zhang X and Xue X: microRNA-1298 inhibits the malignant behaviors of breast cancer cells via targeting ADAM9. Biosci Rep 40: BSR20201215, 2020

19. Attwooll C, Lazzerini Denchi E and Helin K: The E2F family: Specific functions and overlapping interests. EMBO J 23 : 4709-4716, 2004.

20. DeGregori J and Johnson DG: Distinct and overlapping roles for E2F family members in transcription, proliferation and apoptosis. Curr Mol Med 6: 739-748, 2006.

21. Ginsberg D: E2F1 pathways to apoptosis. FEBS Lett 529: $122-125,2002$

22. Helin K, Wu CL, Fattaey AR, Lees JA, Dynlacht BD, Ngwu C and Harlow E: Heterodimerization of the transcription factors E2F-1 and DP-1 leads to cooperative trans-activation. Genes Dev 7: 1850-1861, 1993

23. Strauss M, Lukas J and Bartek J: Unrestricted cell cycling and cancer. Nat Med 1: 1245-1246, 1995.

24. Xu TP, Wang YF, Xiong WL, Ma P, Wang WY, Chen WM, Huang MD, Xia R, Wang R, Zhang EB, et al: E2F1 induces TINCR transcriptional activity and accelerates gastric cancer progression via activation of TINCR/STAU1/CDKN2B signaling axis. Cell Death Dis 8: e2837, 2017.

25. Wang T, Chen X, Qiao W, Kong L, Sun D and Li Z: Transcription factor E2F1 promotes EMT by regulating ZEB2 in small cell lung cancer. BMC Cancer 17: 719, 2017.

26. Ren Z, Kang W, Wang L, Sun B, Ma J, Zheng C, Sun J, Tian Z, Yang X and Xiao W: E2F1 renders prostate cancer cell resistant to ICAM-1 mediated antitumor immunity by NF- $\kappa$ B modulation. Mol Cancer 13: 84, 2014

27. Fueyo J, Gomez-Manzano C, Yung WK, Liu TJ, Alemany R, McDonnell TJ, Shi X, Rao JS, Levin VA and Kyritsis AP: Overexpression of E2F-1 in glioma triggers apoptosis and suppresses tumor growth in vitro and in vivo. Nat Med 4: 685-690, 1998.

28. Kent LN, Bae S, Tsai SY, Tang X, Srivastava A, Koivisto C, Martin CK, Ridolfi E, Miller GC, Zorko SM, et al: Dosage-dependent copy number gains in E2f1 and E2f3 drive hepatocellular carcinoma. J Clin Invest 127: 830-842, 2017.

29. Frietze S, Lupien M, Silver PA and Brown M: CARM1 regulates estrogen-stimulated breast cancer growth through up-regulation of E2F1. Cancer Res 68: 301-306, 2008

30. Sun B, Wingate H, Swisher SG, Keyomarsi K and Hunt KK Absence of $\mathrm{pRb}$ facilitates E2F1-induced apoptosis in breast cancer cells. Cell Cycle 9: 1122-1130, 2010
31. Worku D, Jouhra F, Jiang GW, Patani N, Newbold RF and Mokbel K: Evidence of a tumour suppressive function of E2F1 gene in human breast cancer. Anticancer Res 28: 2135-2139, 2008.

32. Lu G, Li Y, Ma Y, Lu J, Chen Y, Jiang Q, Qin Q, Zhao L, Huang Q, Luo Z, et al: Long noncoding RNA LINC00511 contributes to breast cancer tumourigenesis and stemness by inducing the miR-185-3p/E2F1/Nanog axis. J Exp Clin Cancer Res 37: 289, 2018

33. Cataldo A, Cheung DG, Balsari A, Tagliabue E, Coppola V, Iorio MV, Palmieri D and Croce CM: miR-302b enhances breast cancer cell sensitivity to cisplatin by regulating E2F1 and the cellular DNA damage response. Oncotarget 7: 786-797, 2016.

34. Zhao YX, Liu HC, Ying WY, Wang CY, Yu YJ, Sun WJ and Liu JF: microRNA372 inhibits proliferation and induces apoptosis in human breast cancer cells by directly targeting E2F1. Mol Med Rep 16: 8069-8075, 2017.

35. Solomon LA, Podder S, He J, Jackson-Chornenki NL, Gibson K, Ziliotto RG, Rhee J and DeKoter RP: Coordination of myeloid differentiation with reduced cell cycle progression by PU.1 induction of MicroRNAs targeting cell cycle regulators and lipid anabolism. Mol Cell Biol 37: e00013-17, 2017.

36. Livak KJ and Schmittgen TD: Analysis of relative gene expression data using real-time quantitative PCR and the 2(-Delta Delta C(T)) method. Methods 25: 402-408, 2001.

37. Niknami Z, Muhammadnejad A, Ebrahimi A, Harsani Z and Shirkoohi R: Significance of E-cadherin and Vimentin as epithelial-mesenchymal transition markers in colorectal carcinoma prognosis. EXCLI J 19: 917-926, 2020.

38. Das PK, Siddika MA, Asha SY, Aktar S, Rakib MA, Khanam JA, Pillai $\mathrm{S}$ and Islam F: MicroRNAs, a promising target for breast cancer stem cells. Mol Diagn Ther 24: 69-83, 2020.

39. Wang Z, Li TE, Chen M,Pan JJ and Shen KW: miR-106b-5p contributes to the lung metastasis of breast cancer via targeting CNN1 and regulating Rho/ROCK1 pathway. Aging 12: 1867-1887, 2020.

40. Wen L, Li Y, Jiang Z, Zhang Y, Yang B and Han F: miR-944 inhibits cell migration and invasion by targeting MACC1 in colorectal cancer. Oncol Rep 37: 3415-3422, 2017.

41. Sun X, Cui M, Zhang A, Tong L, Wang K, Li K, Wang X, Sun Z and Zhang H: MiR-548c impairs migration and invasion of endometrial and ovarian cancer cells via downregulation of Twist. J Exp Clin Cancer Res 35: 10, 2016.

42. Li G, Sun L, Mu Z, Liu S, Qu H, Xie Q and $\mathrm{Hu} B$ : MicroRNA-1298-5p inhibits cell proliferation and the invasiveness of bladder cancer cells via down-regulation of connexin 43. Biochem Cell Biol 98: 227-237, 2020.

43. Feliciano A, Garcia-Mayea Y, Jubierre L, Mir C, Hummel M, Castellvi J, Hernández-Losa J, Paciucci R, Sansano I, Sun Y, et al: miR-99a reveals two novel oncogenic proteins E2F2 and EMR2 and represses stemness in lung cancer. Cell Death Dis 8: e3141, 2017.

44. Zhao W, Cui Y, Liu L, Qi X, Liu J, Ma S, Hu X, Zhang Z, Wang Y, $\mathrm{Li} \mathrm{H}$, et al: Splicing factor derived circular RNA circUHRF1 accelerates oral squamous cell carcinoma tumorigenesis via feedback loop. Cell Death Differ 27: 919-933, 2020.

45. Chen X, Wu Q, Depeille P, Chen P, Thornton S, Kalirai H, Coupland SE, Roose JP and Bastian BC: RasGRP3 mediates MAPK pathway activation in GNAQ mutant uveal melanoma. Cancer Cell 31: 685-696.e6, 2017.

46. Hua B, Li Y, Yang X, Niu X, Zhao Y and Zhu X: MicroRNA-361-3p promotes human breast cancer cell viability by inhibiting the E2F1/P73 signalling pathway. Biomed Pharmacother 125: 109994, 2020.

47. Stiewe T and Putzer BM: Role of the p53-homologue p73 in E2F1-induced apoptosis. Nat Genet 26: 464-469, 2000.

48. Peng X, Zhang Y, Gao J and Cai C: MiR-1258 promotes the apoptosis of cervical cancer cells by regulating the E2F1/P53 signaling pathway. Exp Mol Pathol 114: 104368, 2020.

49. Zhang Z, Liu W, Zhao L, Huang Z, Chen X, Ma N, Xu J, Zhang W and Zhang Y: Retinoblastoma 1 protects $\mathrm{T}$ cell maturation from premature apoptosis by inhibiting E2F1. Development 145: dev158139, 2018

50. Udayakumar T, Shareef MM, Diaz DA, Ahmed MM and Pollack A: The E2F1/Rb and p53/MDM2 pathways in DNA repair and apoptosis: Understanding the crosstalk to develop novel strategies for prostate cancer radiotherapy. Semin Radiat Oncol 20: 258-266, 2010

51. Xia W, Liu Y, Cheng T, Xu T, Dong M and Hu X: Correction to: Down-regulated IncRNA SBF2-AS1 inhibits tumorigenesis and progression of breast cancer by sponging microRNA-143 and repressing RRS1. J Exp Clin Cancer Res 39: 60, 2020

This work is licensed under a Creative Commons Attribution-NonCommercial-NoDerivatives 4.0 International (CC BY-NC-ND 4.0) License. 